\title{
QUANTIDADE DE ACIDENTES CAUSADOS POR ANIMAIS PEÇONHENTOS ENTRE OS ANOS DE 2010 A 2014 NO BRASIL
}

\section{ARTIGO ORIGINAL}

SOEIRO, Selthon Macello Capiberibe ${ }^{1}$

FACCO, Lucas ${ }^{2}$

FECURY, Amanda Alves ${ }^{3}$

ARAÚJO, Maria Helena Mendonça de ${ }^{4}$

OLIVEIRA, Euzébio de ${ }^{5}$

DENDASCK, Carla Viana ${ }^{6}$

SOUZA, Keulle Oliveira da ${ }^{7}$

${ }^{1}$ Graduação em andamento em Ciências de Computação.

2 Discente do Curso de Medicina da Universidade Federal do Amapá (UNIFAP).

${ }^{3}$ Biomédica, Doutora em Doenças Tropicais, Professora e pesquisadora do Curso de Medicina da Universidade Federal do Amapá (UNIFAP).

${ }^{4}$ Médica, Professora e pesquisadora do Curso de Medicina da Universidade Federal do Amapá (UNIFAP).

${ }^{5}$ Biólogo, Doutor em Doenças Topicais, Professor e pesquisador do Curso de Educação Física da Universidade Federal do Pará (UFPA).

${ }^{6}$ Teóloga, Doutora em Psicanálise, pesquisadora do Centro de Pesquisa e Estudos Avançados- CEPA.

${ }^{7}$ Socióloga, Mestranda em Estudos Antrópicos na Amazônia, Integrante do Grupo de Pesquisa "Laboratório de Educação, Meio Ambiente e Saúde" (LEMAS/UFPA). 
DIAS, Claudio Alberto Gellis de Mattos ${ }^{8}$

SOEIRO, Selthon Macello Capiberibe. Et al. Quantidade de acidentes causados por animais peçonhentos entre os anos de 2010 a 2014 no Brasil. Revista Científica Multidisciplinar Núcleo do Conhecimento. Ano 05, Ed. 12, Vol. 01, pp. 05-17. Dezembro de 2020. ISSN: 2448-0959, Link de acesso: https://www.nucleodoconhecimento.com.br/saude/quantidade-de-acidentes

\section{RESUMO}

Animais peçonhentos são aqueles que possuem um mecanismo para injetar veneno. Os diferentes venenos ou peçonhas podem causar dor, ruptura dos vasos sanguíneos, queimadura, bolhas, edemas, necrosar o ferimento, hemorragia, vomito de sangue, presença de sangue na urina, sangramento no nariz, transpiração intensa, pressão baixa, hipotermia e problemas neurológicos. O objetivo deste artigo é mostrar a quantidade de acidentes causados por animais peçonhentos entre os anos de 2010 a 2014 no Brasil. Considerados como causas negligenciadas de doenças, os acidentes ocasionados por animais peçonhentos necessitam de maior atenção da saúde pública. Aranhas, escorpiões e serpentes são os principais agentes causadores desses acidentes. Entre as crianças, os meninos são os mais acometidos, sendo a falta de supervisão em atividades diárias uma das principais causas dessa problemática. A produção de soro para tratamento de acidentes ofídicos no Brasil é acentuada, sendo que a quantidade produzida é capaz de abranger a totalidade do número de casos no país. Porém, existe uma problemática em relação à distribuição desse soro, uma vez que áreas de população indígena e regiões de localidades remotas não possuem a disponibilidade adequada, possibilitando consequências negativas para os indivíduos em questão, aumentando a possibilidade de mortes por esse tipo de acidente.

\footnotetext{
${ }^{8}$ Biólogo, Doutor em Teoria e Pesquisa do Comportamento, Professor e pesquisador do Programa de Pós-Graduação em Educação Profissional e Tecnológica (PROFEPT), Instituto Federal do Amapá (IFAP).
} 
Palavras-chave: Epidemiologia, peçonha, veneno.

\section{INTRODUÇÃO}

Animais peçonhentos são aqueles que possuem um mecanismo para injetar veneno, os quais podem ser aguilhões, ferrões ou os dentes (Pinho e Pardal, 2015). Algumas espécies de abelhas, serpentes, vespas, marimbondos, aranhas, escorpiões e lagartas podem ser considerados como animais peçonhentos (BREDT e LITCHTENEKER, 2014; NEIVA, et al., 2019).

Os diferentes venenos ou peçonhas podem causar dor, ruptura dos vasos sanguíneos, queimadura, bolhas, edemas, necrosar o ferimento, hemorragia, vomito de sangue, presença de sangue na urina, sangramento no nariz, transpiração intensa, pressão baixa, hipotermia e problemas neurológicos (LIMA et al., 2017; NEIVA, et al., 2019).

O tratamento de acidentes com animais peçonhentos é feito, na maioria das vezes, por meio de um soro antiveneno que contém anticorpos específicos para combater as toxinas de cada animal, sendo que esse deve ser aplicado o mais rápido possível para evitar o agravamento do caso (SOUZA e MACHADO, 2017).

Para se prevenir de acidentes com serpentes, deve-se usar luvas e botas quando se estiver limpando matos, entulhos, folhas secas, lixo e entre outros, pois tais animais preferem lugares quentes e úmidos. Não se deve colocar mãos em buracos, deve-se evitar a proliferação de ratos, já que estes são alimento das serpentes e, além disso, é necessário evitar acúmulo de mato, madeira, tijolos e outros materiais que possam se tornar abrigo para animais que servem de alimento para as serpentes (BRASIL, 2001).

Para se prevenir de acidentes com aracnídeos, deve-se manter terrenos baldios, jardins e quintais livres de entulhos, matos, folhas secas e materiais de construção, evitando assim que eles encontrem abrigo. Além disso, deve-se: evitar plantas com folhagem densa perto de muros; sacudir roupas e sapatos antes de usar; utilizar luvas 
e calçados quando manusear e andar em lugares que possam conter esses animais; vedar aberturas onde aracnídeos possam atravessar (principalmente em período noturno, por conta de seus hábitos); colocar telas em ralos, pias e tanques; evitar a proliferação de insetos que são o alimento dos aracnídeos (uma das medidas é manter lixos domésticos em locais fechados para evitar baratas e moscas); afastar camas das paredes e não deixar mosqueteiros e lençóis de cama encostarem no chão; evitar matar os predadores dos aracnídeos (sapos, aves, lagartos, galinhas, gansos, macacos e entre outros) (BRASIL, 2001).

O número de casos no Brasil entre os anos de 1986 a 2016 foram 2.183.989. O número de casos por regiões, no Brasil, entre os anos 1986 a 2016, são: região Norte: 233.586; região Nordeste: 624.615; região Sudeste: 758.238; região Sul: 427.442; região Centro-Oeste: 140.108. O número de casos no Amapá entre os anos de 1986 a 2016 no Amapá 8463 (BRASIL, 2017).

\section{OBJETIVOS}

Mostrar a quantidade de acidentes causados por animais peçonhentos entre os anos de 2010 a 2014 no Brasil.

\section{MÉTODO}

A pesquisa foi realizada no banco de dados DATASUS (http://datasus.saude.gov.br/). Foram coletados dados nacionais de acordo com as seguintes etapas: A) Acessou-se o link datasus.saude.gov.br, deslizou-se a seta com o mouse até a aba "Acesso a Informação", e depois foi-se a aba "Informações de Saúde (TABNET)", clicou-se em "Epidemiológicas e Morbidade". Na próxima página clicou-se em "Doenças e Agravos de Notificação - De 2007 em diante (SINAN)". Na próxima página selecionou-se "Acidentes por Animais Peçonhentos. Na caixa "Abrangência Geográfica" optou-se por "Brasil por Região, UF e Município". A partir dai seguiram-se os passos: A) $\mathrm{Na}$ linha, selecionou-se "Ano acidente"; na coluna "Não ativa", e no conteúdo "Notificações". Todos os dados coletados neste e nos próximos passos são entre 2010 a 2014. B) Na linha, selecionou-se "Ano acidente"; na coluna "Mês acidente", e no 
conteúdo "Notificações". C) Na linha, selecionou-se "Ano acidente"; na coluna "Região de notificação", e no conteúdo "Notificações". D) Na linha, selecionou-se "Ano acidente"; na coluna "Faixa etária", e no conteúdo "Notificações". E) Na linha, selecionou-se "Ano acidente"; na coluna "Raça", e no conteúdo "Notificações". F) Na linha, selecionou-se "Ano acidente"; na coluna "Sexo", e no conteúdo "Notificações". G) Na linha, selecionou-se "Ano acidente"; na coluna "Gestante", e no conteúdo "Notificações". H) Na linha, selecionou-se "Ano acidente"; na coluna "Tempo picada/atendimento", e no conteúdo "Notificações". I) Na linha, selecionou-se "Ano acidente"; na coluna "Tipo de Acidente", e no conteúdo "Notificações". J) Na linha, selecionou-se "Ano acidente"; na coluna "Classifica. Final", e no conteúdo "Notificações". K) Na linha, selecionou-se "Ano acidente"; na coluna "Evolução caso", e no conteúdo "Notificações"

A compilação dos dados foi feita dentro do aplicativo Excel, componente do pacote Office da Microsoft Corporation. A pesquisa bibliografia foi realizada em artigos científicos, utilizando-se para busca computadores do laboratório de informática do Instituto Federal de Educação, Ciências e Tecnologia do Amapá, Campus Macapá, situado na: Rodovia BR 210 KM 3, s/n - Bairro Brasil Novo. CEP: 68.909-398, Macapá, Amapá, Brasil.

\section{RESULTADOS}

A figura 1 mostra a quantidade de acidentes causados por animais peçonhentos entre os anos de 2010 a 2014, indicando um aumento a cada ano. 
Figura 1 Mostra o número de casos de acidentes causados por animais peçonhentos no Brasil entre os anos de 2010 e 2014.

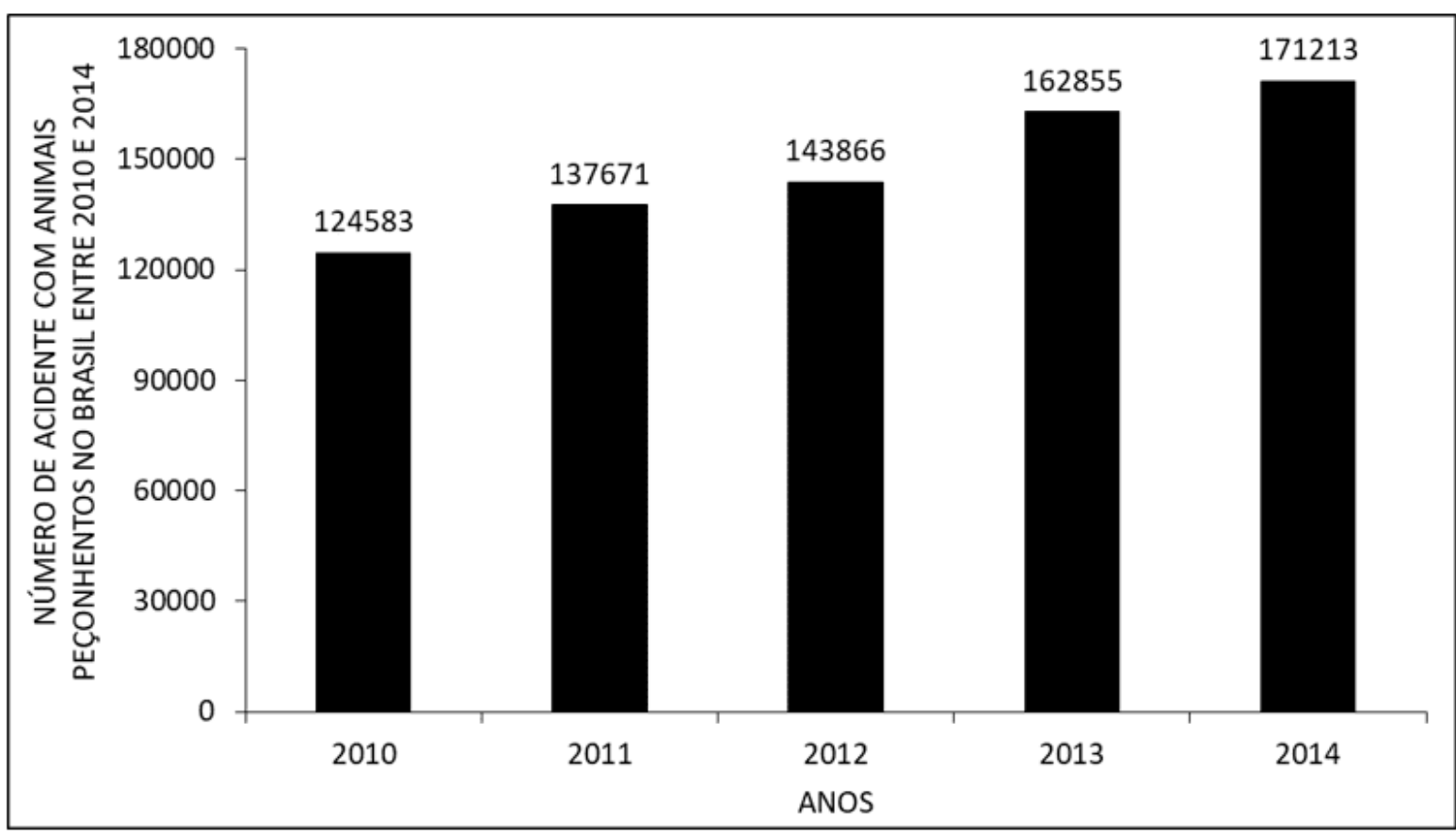

A figura 2 mostra o número de acidentes causados por animais peçonhentos por meses do ano entre os anos de 2010 a 2014. O maior número ocorre em janeiro, apresentando uma queda em fevereiro, aumentando novamente em março e novamente declinando até chegar julho. Este é o mês com o menor número de casos, ocorrendo aumento nos meses subsequentes. 
Figura 2 Mostra o número de casos de acidentes causados por animais peçonhentos no Brasil entre os anos de 2010 e 2014, por meses do ano.

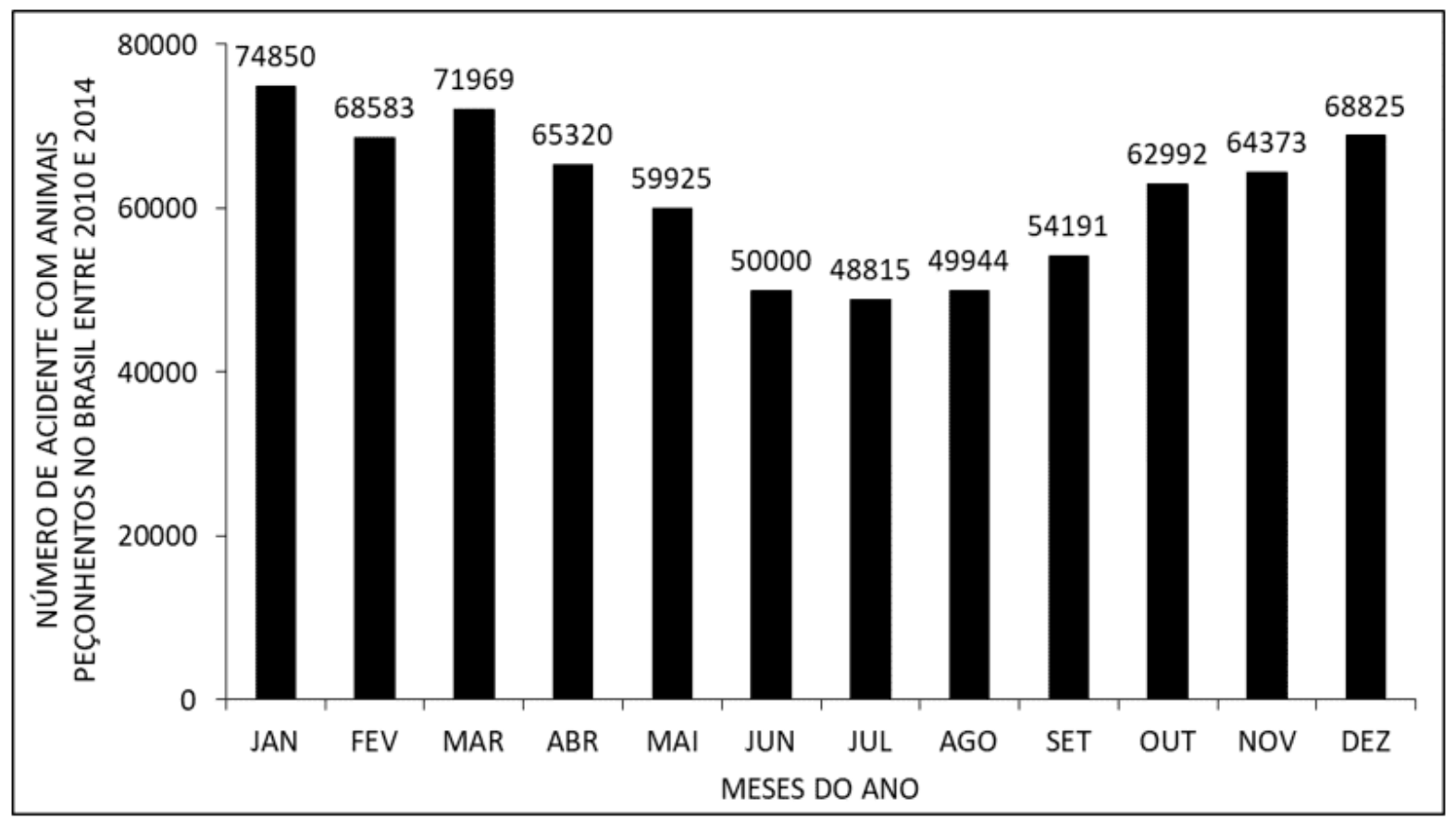

A figura 3 mostra o número de notificações de acidentes causados por animais peçonhentos do Brasil entre os anos de 2010 e 2014, por regiões do país. O maior número de casos ocorre na região sudeste seguido, respectivamente, pelas regiões nordeste, sul, norte e centro-oeste. 
Figura 3 Mostra o número de casos de acidentes causados por animais peçonhentos no Brasil entre os anos de 2010 e 2014, por regiões do país.

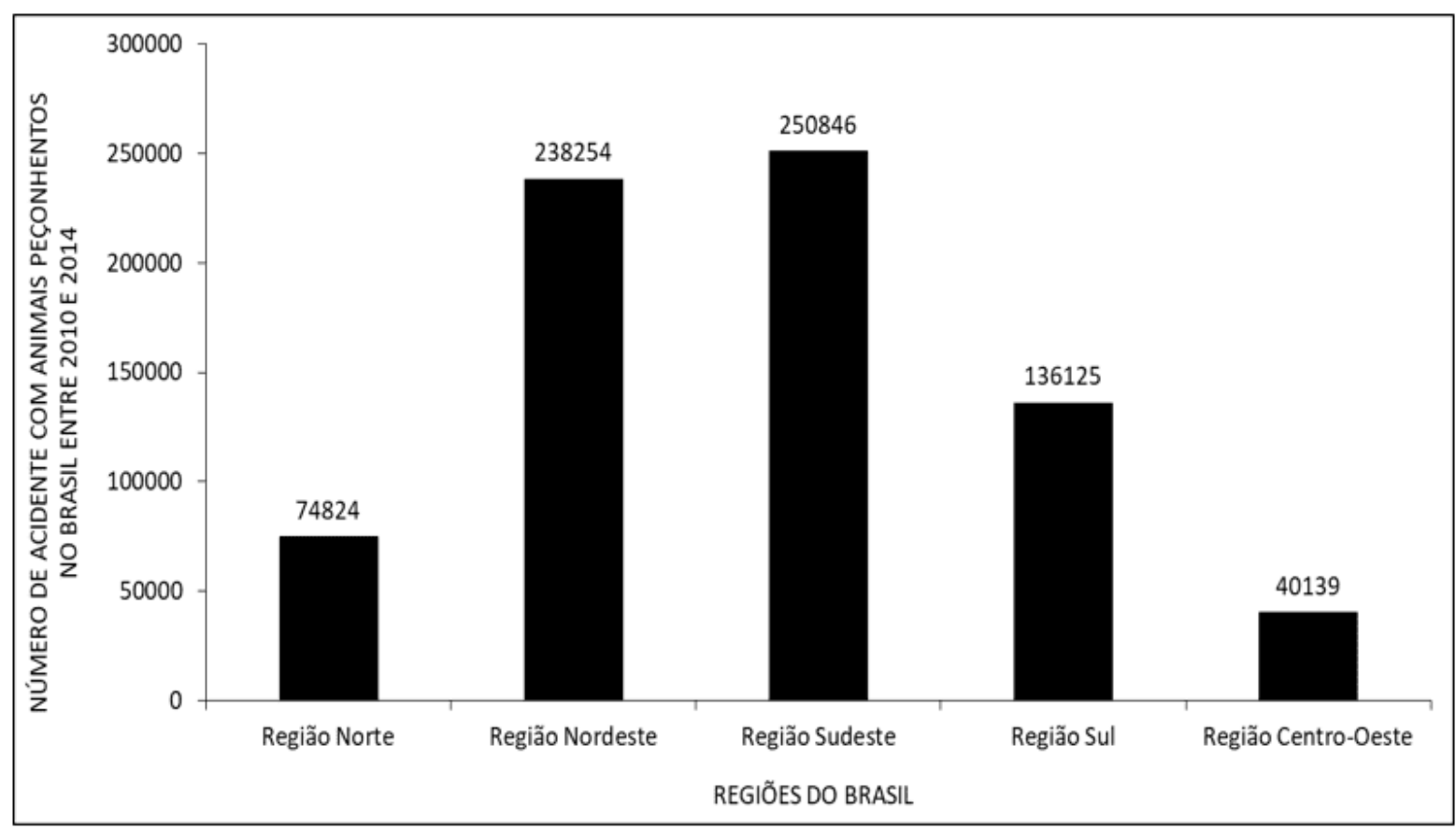

A figura 4 mostra o número de notificações de acidentes causados por animais peçonhentos do Brasil entre os anos de 2010 e 2014, por gênero. O maior número de casos acontece com homens. 
Figura 4 Mostra o número de casos de acidentes causados por animais peçonhentos no Brasil entre os anos de 2010 e 2014, por gênero.

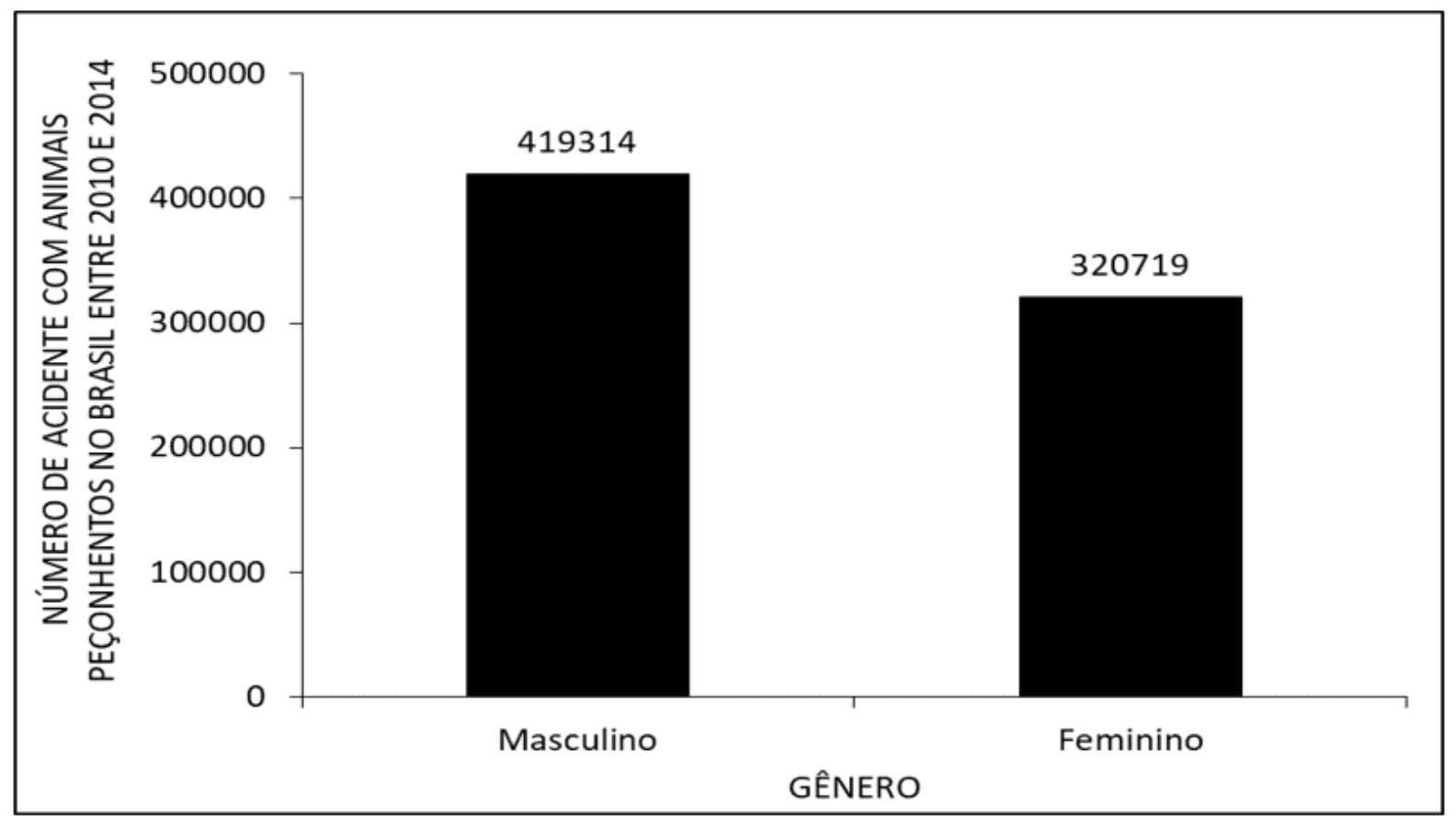

A figura 5 mostra o número de notificações de acidentes causados por animais peçonhentos do Brasil entre os anos de 2010 e 2014, por faixa etária. O maior número de casos, segundo os dados, ocorre com pessoas entre 20 e 39 anos. $O$ segundo maior número de casos aparece no grupo entre 40 e 59 anos. 
Figura 5 Mostra o número de casos de acidentes causados por animais peçonhentos no Brasil entre os anos de 2010 e 2014, por faixa etária.

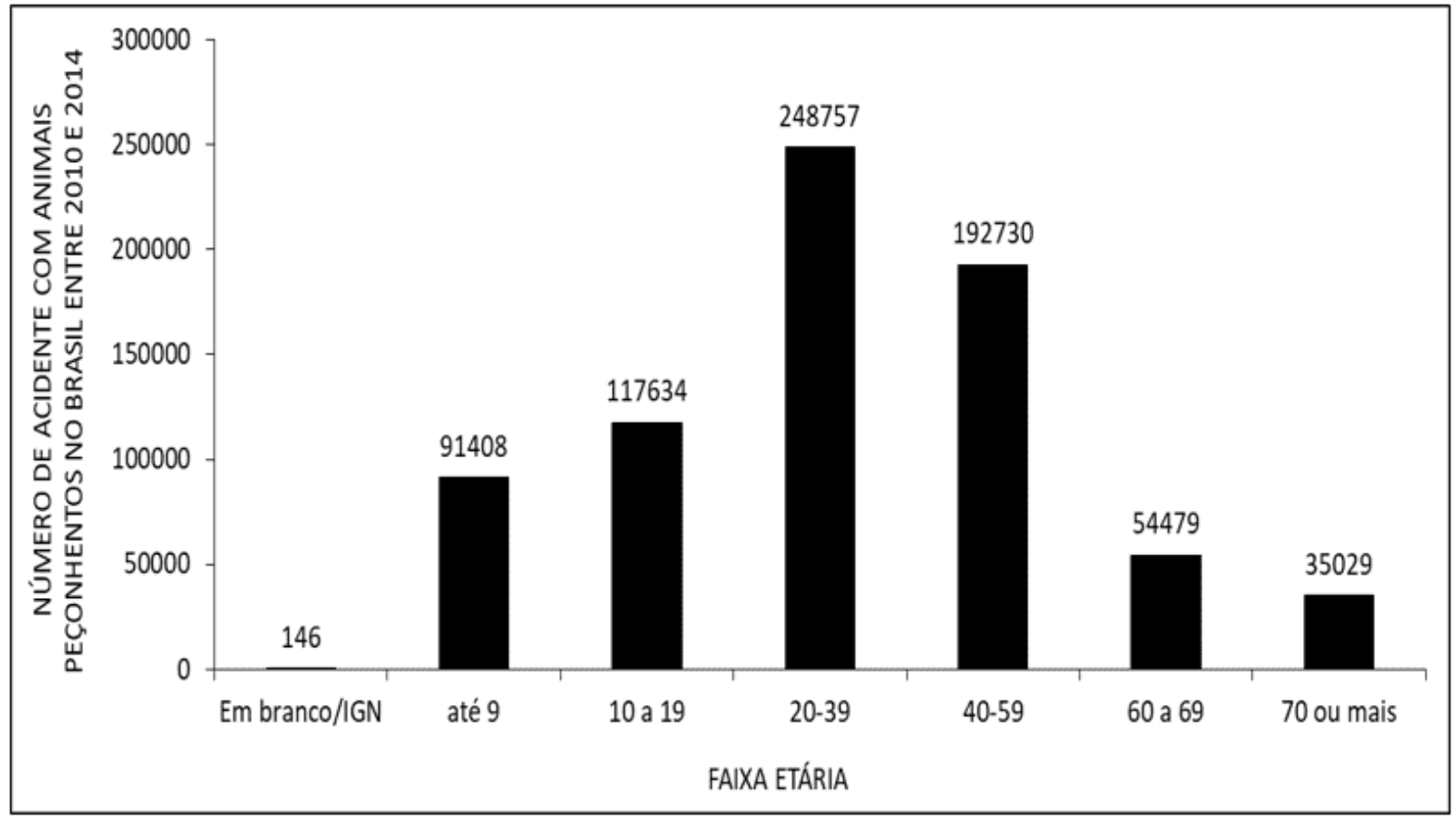

A figura 6 mostra o número de notificações de acidentes causados por animais peçonhentos do Brasil entre os anos de 2010 e 2014, por etnia. O maior número de casos ocorre com pessoas de etnia parda, seguidas por pessoas declaradas brancas e pessoas pretas, respectivamente. 
Figura 6 Mostra o número de casos de acidentes causados por animais peçonhentos no Brasil entre os anos de 2010 e 2014, por etnia.

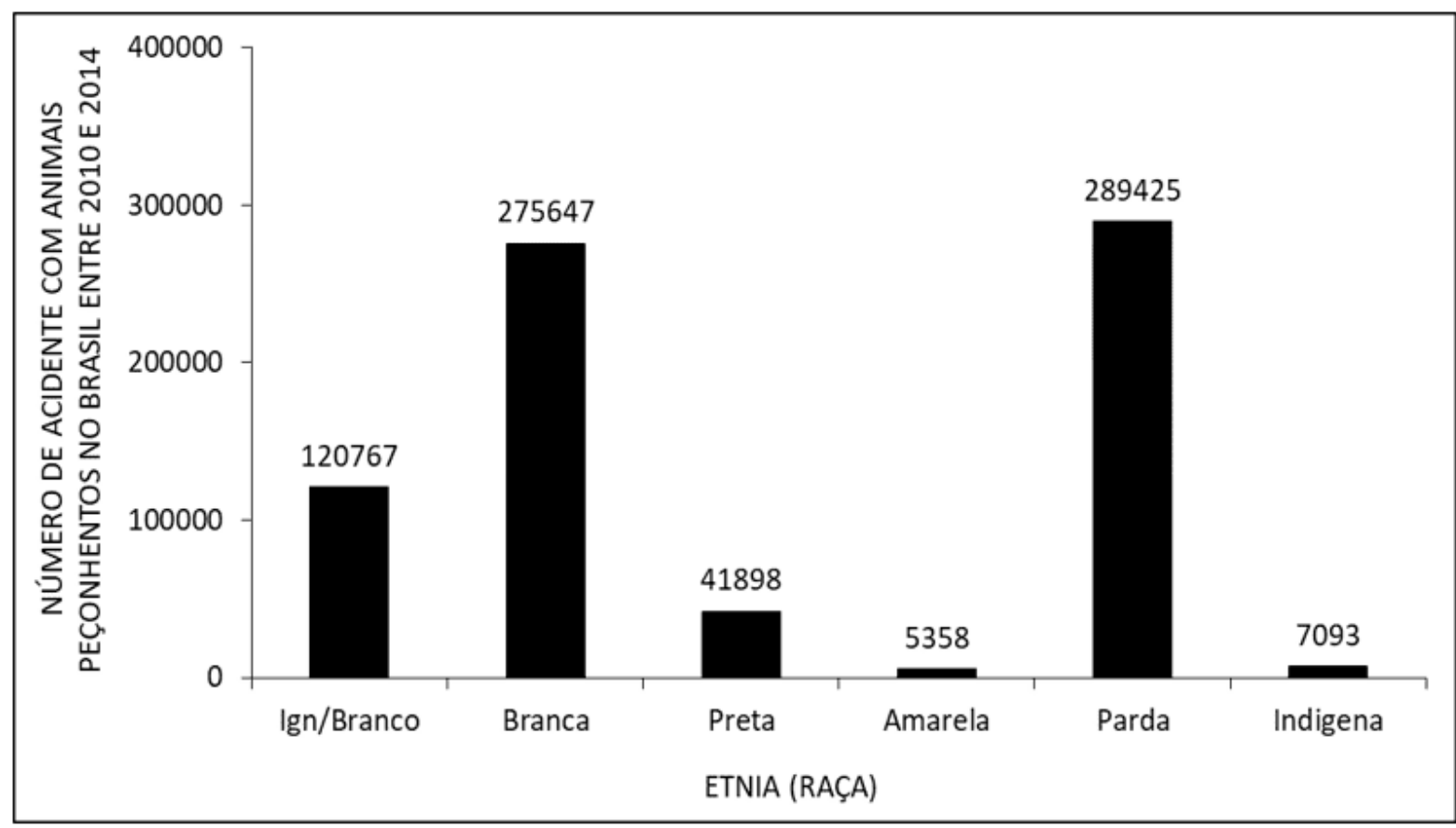

A figura 7 mostra o número de notificações de acidentes causados por animais peçonhentos do Brasil entre os anos de 2010 e 2014, por tipo de acidente. O maior número de casos ocorreu em acidentes com envolvimento de escorpiões. 
Figura 7 Mostra o número de casos de acidentes causados por animais peçonhentos no Brasil entre os anos de 2010 e 2014, por tipo de acidente.

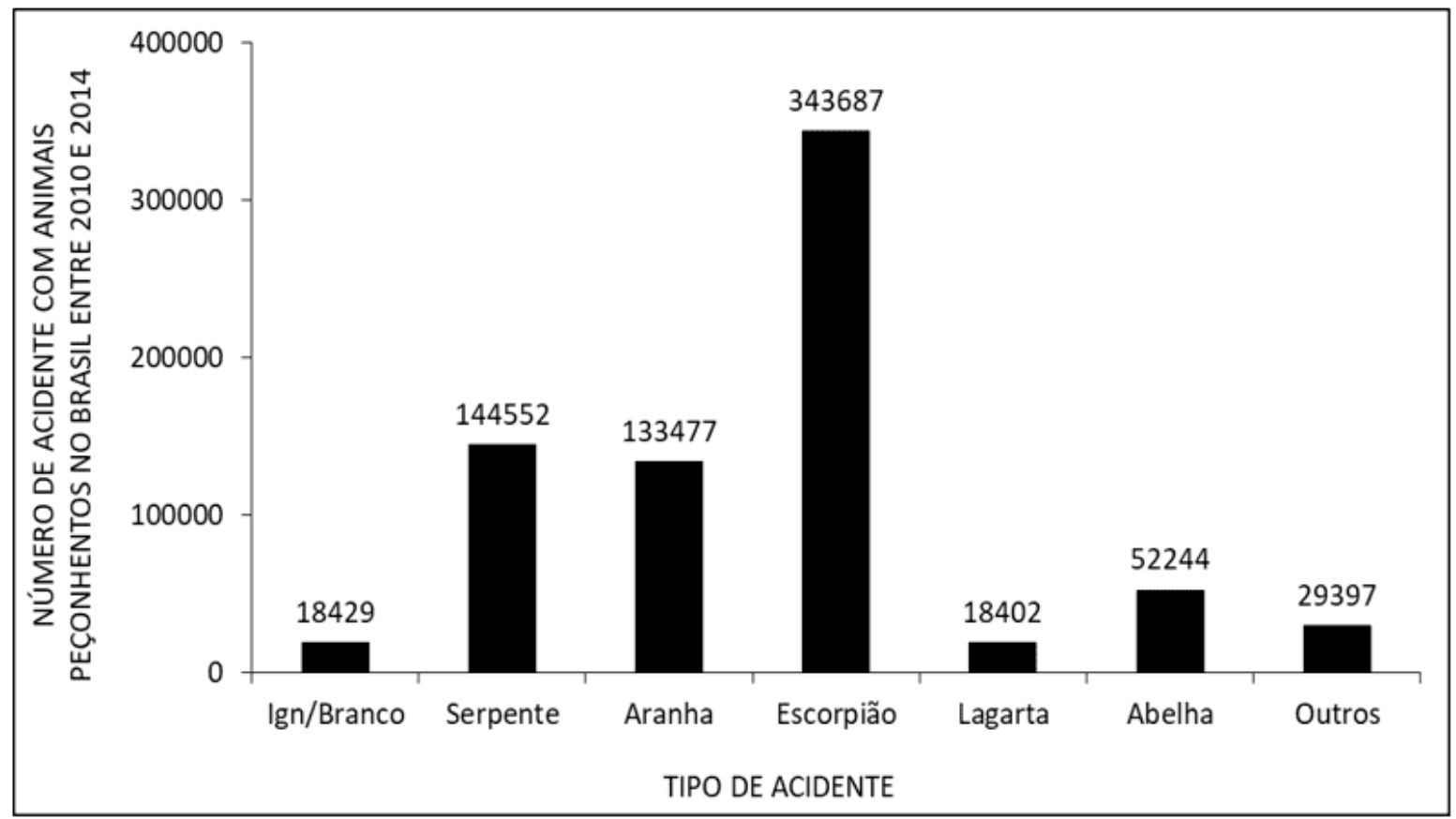

A figura 8 mostra o número de notificações de acidentes causados por animais peçonhentos do Brasil entre os anos de 2010 e 2014, de acordo com os estágios da gravidez. O maior número de casos acontece com gestantes no segundo trimestre, seguidas por gestantes no primeiro e terceiro trimestre, respectivamente. 
Figura 8 Mostra o número de casos de acidentes causados por animais peçonhentos no Brasil entre os anos de 2010 e 2014, de acordo com os estágios da gravidez.

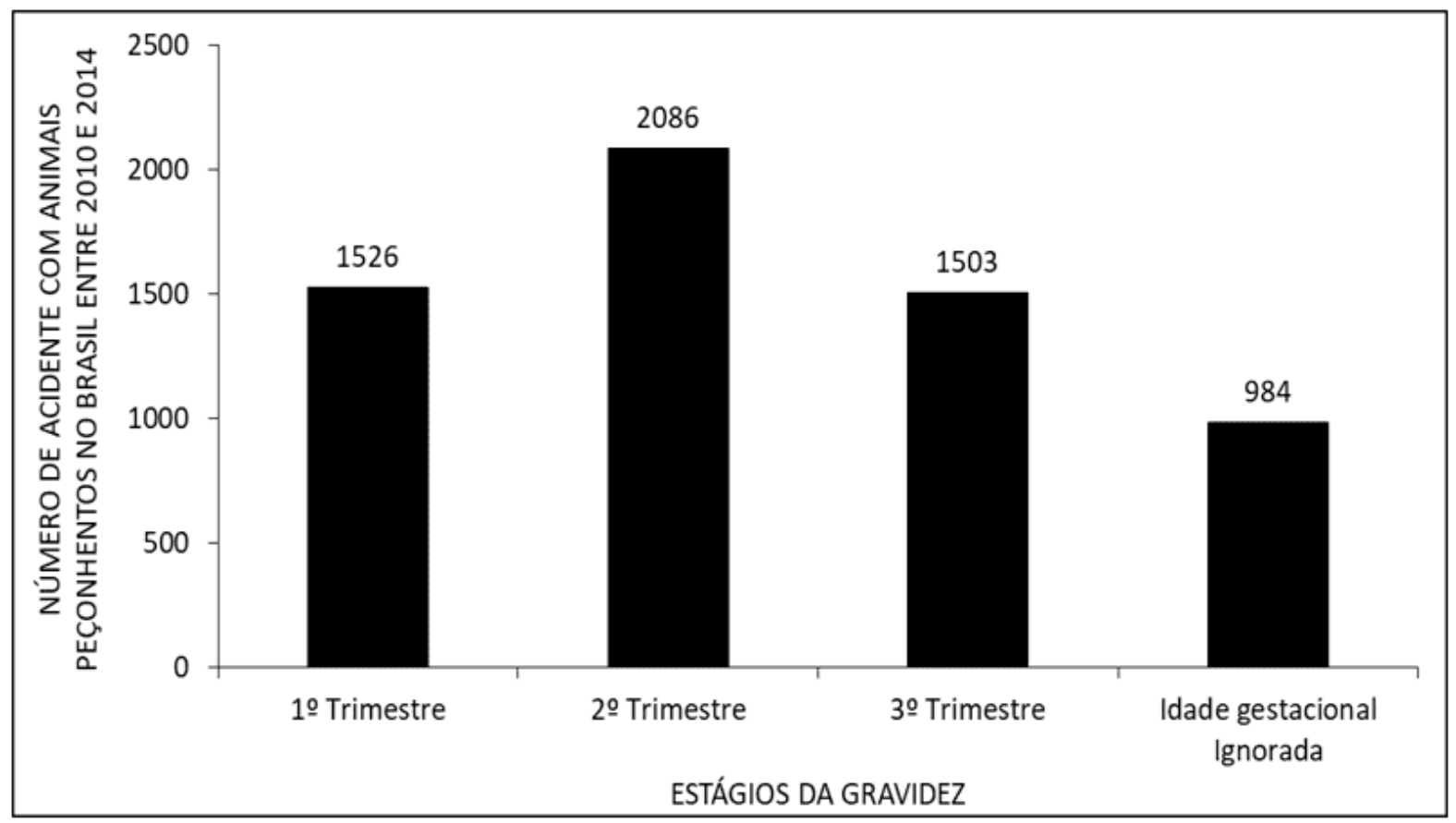

A figura 9 mostra o número de notificações de acidentes causados por animais peçonhentos do Brasil entre os anos de 2010 e 2014, de acordo com o tempo em horas entre a picada e o atendimento. Os dados mostram que o maior número de pessoas é atendida entre 0 e 3 horas após o acidente. 
Figura 9 Mostra o número de casos de acidentes causados por animais peçonhentos no Brasil entre os anos de 2010 e 2014, de acordo com o tempo em horas entre a picada e $o$ atendimento.

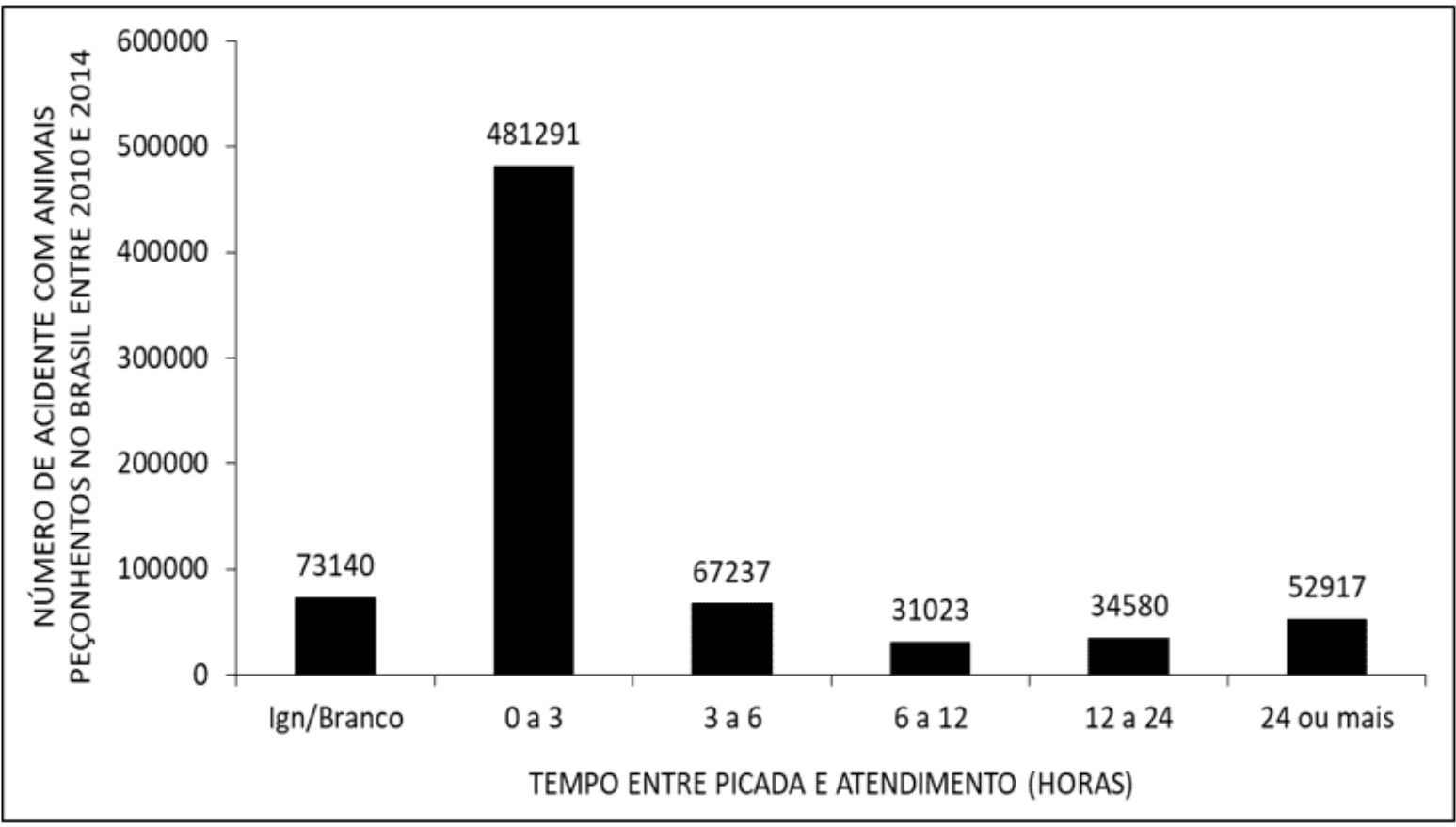

A figura 10 mostra o número de notificações de acidentes causados por animais peçonhentos do Brasil entre os anos de 2010 e 2014, por classificação final do acidente. O maior número de casos teve como classificação final do acidente de grau leve. 
Figura 10 Mostra o número de casos de acidentes causados por animais peçonhentos no Brasil entre os anos de 2010 e 2014, por classificação final do acidente.

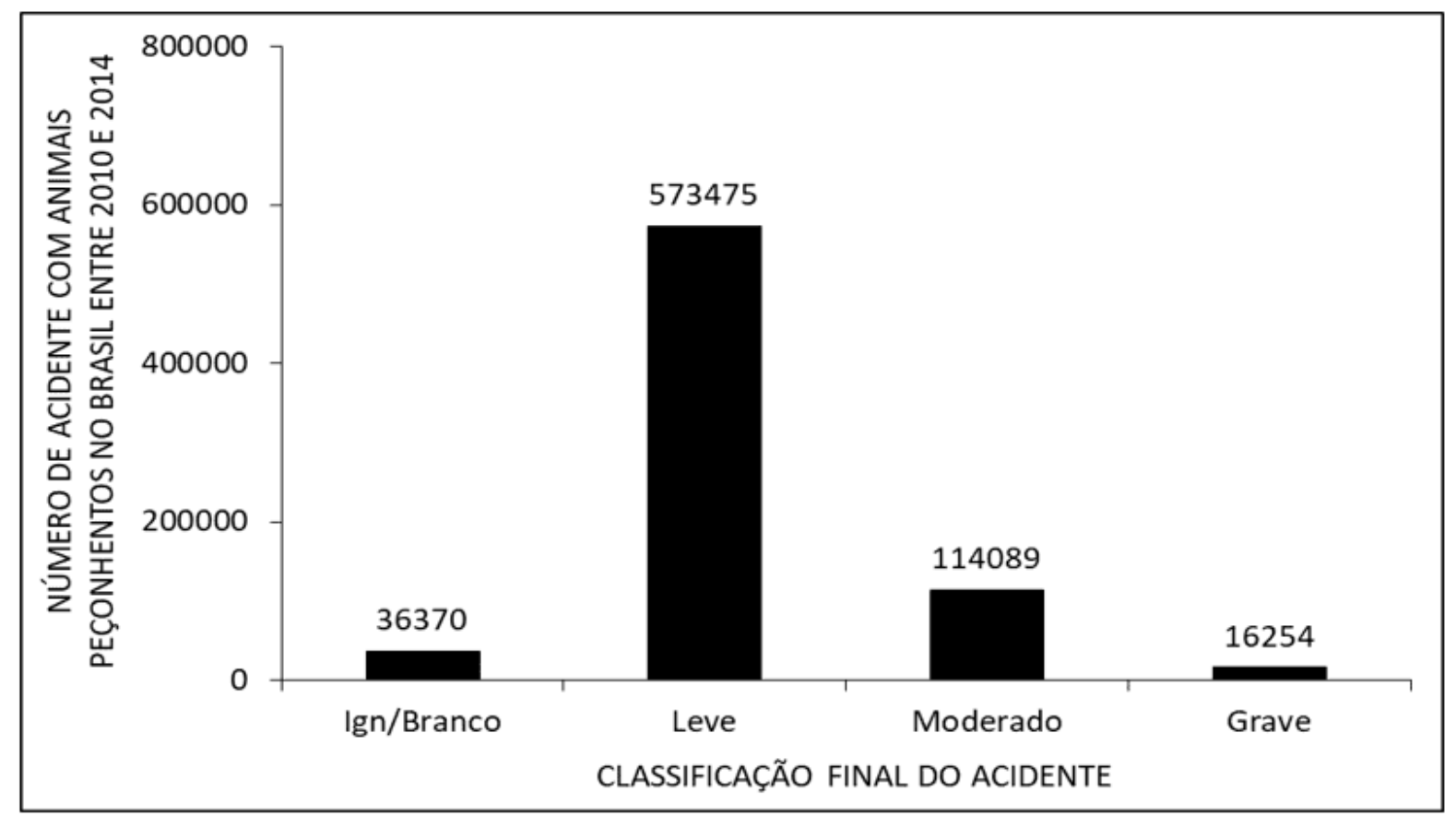

A figura 11 mostra o número de notificações de acidentes causados por animais peçonhentos do Brasil entre os anos de 2010 e 2014, por evolução do caso. O maior número de casos foi curado, com uma mínima quantidade chegando a óbito. 
Figura 11 Mostra o número de casos de acidentes causados por animais peçonhentos no Brasil entre os anos de 2010 e 2014, por evolução do caso.

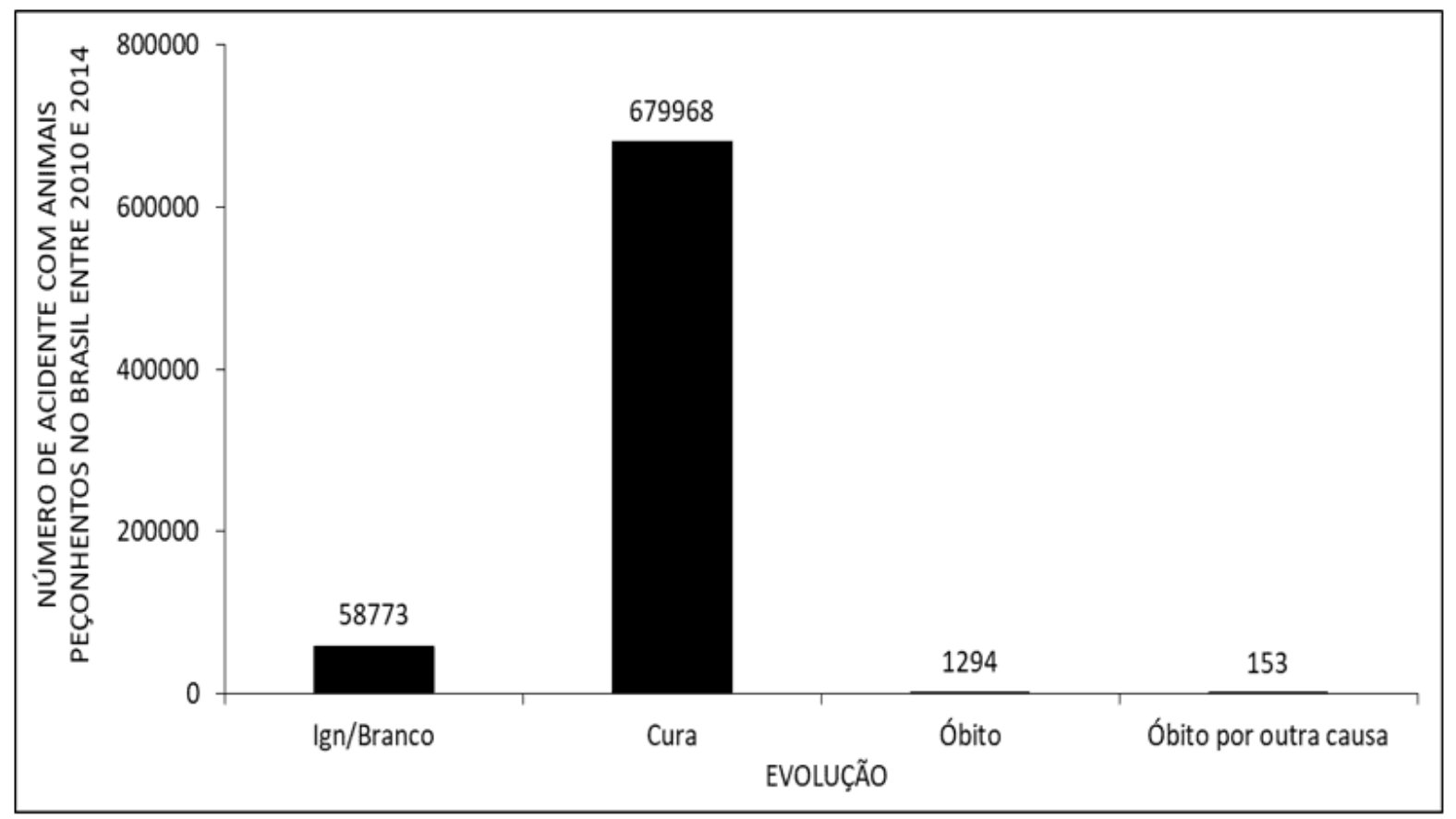

\section{DISCUSSÃO}

Os acidentes ocasionados por animais peçonhentos são considerados como causas negligenciadas de doenças, sendo sua ocorrência maior em áreas rurais e em países cuja pobreza é abrangente. Capazes de gerar uma série de prejuízos, tais acidentes são capazes de ocasionar consequências a nível orgânico e socioeconômico, uma vez que justificam a necessidade de investimentos em métodos profiláticos e em soros para o tratamento de tais acometimentos (SALOMÃO et al., 2018). Considerados como emergência clínica (ou seja, em que há necessidade de atenção imediata ao paciente), são ocasionados por uma série de animais peçonhentos, sendo eles escorpiões, aranhas e serpentes. Em 2013, no Brasil, houve registro de 158.002 casos de acidentes com animas peçonhentos, sendo a maioria (cerca de $78 \%$ do total) ocasionada por serpentes (SILVA et al., 2015). Os acidentes de trabalho que envolvem causas pautadas em animais peçonhentos não são notificados de maneira ideal, sendo subnotificados. Porém, houve aumento de tais casos, levando em consideração um período que abrange de 2007 a 2017 (BRASIL, 2019). 
A região Sudeste é a campeã em número de acidentes ocasionados por animais peçonhentos, sendo serpentes e escorpiões os maiores causadores de tais ocorrências. Dentre tais, os escorpiões têm se mostrado como os maiores causadores de tal problemática, uma vez que encontram nas áreas urbanas boa adaptação ao meio, fator esse que propicia a reprodução e consequente proliferação desse animal na região. Grande parcela dos acidentes escorpiônicos deflagram consequências leves ao organismo humano e não necessitam do uso de soroterapia. Porém, nos demais casos, pode haver variação ampla das consequências de indivíduo para indivíduo, sendo a morte um possível desfecho, caso não haja tratamento adequado. Além disso, podem haver sequelas de tais acidentes, de modo a prejudicar a dinâmica diária do indivíduo, dificultando, até mesmo, seu trabalho (LIMA et al., 2020).

Grande parcela dos casos de acidentes com animais peçonhentos (sua maioria) ocorre com indivíduos do sexo masculino, sendo essa afirmação válida para a ampla maioria dos animais peçonhentos. Em especial, dentre os acidentes ofídicos, o perfil epidemiológico mais comum é o de homens trabalhadores rurais, cuja idade está entre 15 e 49 anos (BRASIL, 2019). Meninos costumam sofrer mais acidentes por animais peçonhentos em vista de aspectos como a falta de supervisão em atividades lúdicas ao ar livre, além de outros quesitos socioculturais (NEIVA et al., 2019). A faixa etária que compreende o maior número de casos é da de 20 a 39 anos, sendo que, entre o período de 2009 a 2013, houve aumento de casos nessa faixa (SILVA et al., 2015a). Em vista de dados coletados, o maior número de indivíduos afetados por acidentes com animais peçonhentos é de etnia parda, seguidos por brancos e negros.

Dentre os acidentes e óbitos que são ocasionados por animais peçonhentos, os escorpiões são os maiores responsáveis dentro do período em estudo. Na região Sudeste (região em que há maior predominância de acidentes por animais peçonhentos), as causas escorpiônicas são responsáveis pela maior média dos óbitos e acidentes dessa categoria (LIMA et al., 2020). Dentre os acidentes de trabalho que que ocorrem por causas escorpiônicas, as partes do corpo mais acometidas são as mãos, pés e braços, levando em consideração o período de 2007 a 2017 (BRASIL, 2019). 
Os acidentes botrópicos correspondem ao ofidismo mais comum no país, sendo que representa cerca de $90 \%$ do total. O veneno possui uma série de ações a nível orgânico no indivíduo, sendo capaz de ocasionar efeitos proteolíticos, coagulantes e hemorrágicos. Além disso, dor, edema, equimoses e sangramento na região da picada são comuns. Pode haver também o aparecimento de bolhas e infartamento de grupos ganglionares (a necrose da região pode ocorrer, mas não está sempre presente). Em gestantes, além das manifestações em questão, ocorre risco de hemorragia uterina, caracterizando um caso de maior gravidade (BRASIL, 2001).

Mediante os dados apresentados, dentre os indivíduos que sofreram um acidente ocasionado por animais peçonhentos, a maioria é atendida pelos serviços de saúde em até 3 horas após 0 acidente. $O$ tempo entre a picada e 0 atendimento deve ser 0 menor possível, sendo que, segundo dados relativos ao estado do Rio Grande do Sul, conforme aumenta o tempo para que ocorra 0 atendimento, aumenta-se a possibilidade de consequências negativas ao indivíduo, como a diminuição do número de curados e aumento da letalidade. Embora o maior número de óbitos ocorra entre o sexo masculino, o sexo feminino apresenta maior taxa de letalidade. Em caso de pacientes idosos com 80 anos ou mais, observou-se maior índice de letalidade comparado às outras faixas etárias (DORNELES, 2009).

Os acidentes por animais peçonhentos, em sua maior quantidade, não representaram classificação pautada em estado de gravidade, ou seja, a maioria foi classificado como grau leve. A maior taxa de gravidade e letalidade costuma ocorrer em crianças e indivíduos mais idosos (maiores de 80 anos) (DORNELES, 2009). Em relação aos acidentes escorpiônicos, a maioria pode ser tratada em uma unidade de saúde localizada nas proximidades do paciente, não necessitando de soroterapia (LIMA et al., 2020).

O Brasil é um dos países que mais produzem soros antivenenos a nível mundial (cerca de 400.000 ampolas). Nacionalmente, o tratamento é fornecido pelo Sistema Único de Saúde, sendo o Brasil o país cuja distribuição gratuita de soro antiofídico é feita de forma mais abrangente e com maior facilidade, uma vez que está disponível para quaisquer que sejam os acidentados. A quantidade produzida nacionalmente é 
acertada para que possa atender a $100 \%$ dos indivíduos brasileiros. Porém, ainda existem complicações que devem ser resolvidas em relação ao acesso a todas as regiões de forma completa, sendo as áreas indígenas e regiões remotas locais com menor disponibilidade de soro (CUNHA, 2017).

\section{CONCLUSÃO}

Considerados como causas negligenciadas de doenças, os acidentes ocasionados por animais peçonhentos necessitam de maior atenção da saúde pública, sendo que é necessária a melhoria do sistema de notificação dos casos e a disponibilização mais ampla de informações acerca do assunto para a população em geral. Aranhas, escorpiões e serpentes são os principais agentes causadores desses acidentes.

O perfil epidemiológico mais frequente em acidentes ofídicos é do sexo masculino, trabalhadores rurais, entre 15 e 49 anos. Entre as crianças, os meninos são os mais acometidos, sendo a falta de supervisão em atividades diárias uma das principais causas dessa problemática.

Grande parte dos acidentes escorpiônicos geram consequências leves ao organismo humano e não implicam necessidade do uso de soroterapia. Nos demais casos, entretanto, pode ocorrer ampla variação das consequências de paciente para paciente, sendo que, caso não haja tratamento ministrado de forma adequada, o paciente pode ser ir a óbito.

A maioria dos casos costuma ser atendida pelos serviços de saúde em até 3 horas após $\mathrm{o}$ acidente. $\mathrm{O}$ tempo entre $\mathrm{o}$ acidente e $\mathrm{o}$ atendimento deve ser o menor possível, sendo que, conforme aumenta o tempo para que ocorra o atendimento, a possibilidade de consequências negativas ao indivíduo aumenta proporcionalmente, com diminuição da taxa de cura e aumento da letalidade.

Grande parte dos pacientes que passam por acidentes escorpiônicos não necessitam de soroterapia, sendo que podem recorrer ao tratamento adequado em unidades de saúde que estejam localizadas nas proximidades do local em que ocorreu o acidente, 
de modo que a locomoção seja mais rápida e a consequente taxa de melhora seja mais elevada.

A produção de soro para tratamento de acidentes ofídicos no Brasil é acentuada, sendo que a quantidade produzida é capaz de abranger a totalidade do número de casos no país. Porém, existe uma problemática em relação à distribuição desse soro, uma vez que áreas de população indígena e regiões de localidades remotas não possuem a disponibilidade adequada, possibilitando consequências negativas para os indivíduos em questão, aumentando a possibilidade de mortes por esse tipo de acidente.

\section{REFERÊNCIAS}

BRASIL, Fundação Nacional de Saúde. Manual de Diagnóstico e tratamento de acidentes por animais peçonhentos, $2^{\mathrm{a}}$ ed., Brasília, 2001.

BRASIL, Portal da saúde. Série Histórica de Casos - Acidente Por Animais Peçonhentos. 2017. Acessado em 26 de setembro de 2017<http://portalarquivos.saude.gov.br/images/pdf/2017/abril/28/1 -

SerieHistorica_1986-2016.pdf>

BRASIL. Secretaria de Vigilância em Saúde. Ministério da Saúde. Boletim Epidemiológico 11: Acidentes de trabalho por animais peçonhentos entre trabalhadores do campo, floresta, águas, Brasil 2007 a 2017, v. 50, 2019.

BREDT C. S, LITCHTENEKER K. Avaliação Clínica e Epidemiológica dos acidentes com animais peçonhentos atendidos no Hospital Universitário do Oeste do Paraná 2008- 2012. Rev. Med. Res., Curitiba, v.16, n.1, p. 11-17, jan./mar. 2014.

CARMO É. A, NERY A. A, JESUS C. S, CASOTTI C. A. Internaçoes hospitalares por causas externas envolvendo contato com animais em um hospital geral do interior da Bahia, 2009-2011. Epidemiol. Serv. Saude, Brasília, p.105-114, jan./mar. 2016. 
CUNHA, L. E. R. Soros antiofídicos: história, evolução e futuro. Journal Health NPEPS, v. 2, supl. 1, p. 1-4, 2017.

DORNELES, A. L. Frequência de acidentes por animais peçonhentos ocorridos no Rio Grande do Sul, 2001 - 2006. Trabalho de Conclusão de curso, Especialização em Saúde Pública, Proto Alegre, RS. 2009.

LIMA E. C. F, FARIA M. D, MORAIS R. M. R. B, OLIVEIRA L. M. S. R, LIMA E. H. F, COSTA C. S. Interações entre meio ambiente, atendimentos antirrábicos e acidentes por animais peçonhentos no município de Petrolina(PE). Saúde Meio Ambient, v.6, n.1, p.54-70, jan./jun. 2017.

LIMA, C. A.; LEAL, A. L. R.; MANGUEIRA, S. A. L.; COSTA, S. M.; SANTOS, D. F. Vigilância em saúde: acidentes e óbitos provocados por animais peçonhentos na região sudeste Brasil, 2005-2015. Revista de Pesquisa: Cuidado é Fundamental Online, v. 12, p. 20-28, 2020.

LOPES A. B, OLIVEIRA A. A, DIAS F. C. F, SANTANA V. M. X, OLIVEIRA V. S, LIBERATO A. A, CALADO E. J. R, LOBO P. H. P, GUSMÃO K. E, GUEDES V. R. Perfil Epidemiológico dos Acidentes por Animais Peçonhentos na Região Norte Entre os Anos entre 2012 e 2015: Uma Revisão. Revista de Patologia do Tocantins, v.4, n.2, p.36-40, 2017.

NEIVA, C.A.C et al. Caracterização epidemiológica das intoxicações exógenas por substâncias nocivas e acidentes por animais peçonhentos em crianças no Estado do Amapá. Revista Científica Multidisciplinar Núcleo do Conhecimento, v. 01, p. 4166, 2019. https://www.nucleodoconhecimento.com.br/saude/caracterizacaoepidemiologica

SALOMÃO, M. G.; LUNA, K. P. O.; MACHADO, C. Epidemiologia dos acidentes por animais peçonhentos e a distribuição de soros: estado de arte e a situação mundial. Rev. Salud Pública, v. 20, n. 4, p. 523-529, 2018. 
SANTANA V. T. P, SUCHARA E. A. Epidemiologia dos acidentes com animais peçonhentos registrados em Nova Xavantina - MT. Revista de Epidemiologia e Controle de Infecção, v.5, n.3, p.141-146, 2015.

SILVA C. T., PARDAL P. P. Atividades Lúdicas Na Prevenção De Acidentes Por Animais Peçonhentos Em Estudantes Da Rede Pública Da Região Metropolitana De Belém. Revista Universo \& Extensão, v.3, n.3, 2015.

SILVA, A. M.; BERNARDE, P. S.; ABREU, L. C. Acidentes com animais peçonhentos no Brasil por sexo e idade. Journal of Human Growth and Development, v. 25, n. 1, p. 54-62, 2015a.

SILVA J. H, GIANSANTE S, SILVA R. C. R, SILVA G. B, SILVA L. B, PINHEIRO L. C. B. Perfil Epidemiológico dos Acidentes com Animais Peçonhentos em Tangará da Serra-Mt, Brasil (2007-2016). Journal Health NPEPS, p.5-15, 2017.

SOUZA C. M. V, MACHADO C. Animais peçonhentos de importância médica no município do rio de janeiro. Journal Health NPEPS, p.16-39 2017.

Enviado: Dezembro, 2020.

Aprovado: Dezembro, 2020. 